\title{
Catenanes and rotaxanes of the amide type
}

\author{
F. Vögtle*, R. Jäger, M. Händel, S. Ottens-Hildebrandt \\ Institut für Organische Chemie und Biochemie der Universität Bonn, Gerhard- \\ Domagk-Str. 1, 53121 Bonn, Germany
}

\begin{abstract}
New catenane (cf. 3) and rotaxane (cf. 26) types have been obtained in remarkable yields via supramolecular template syntheses. The amide-based mechanically bonded structures can be designed by appropriate choice of building units. The selective formation of stable out/out, in/in and in/out [2]catenane isomers (cf. Scheme 2), which were separated, allowed conclusions concerning their mechanism of formation. It was demonstrated that one of the two macromonocycles of the catenane molecule forms initially and acts as a host cavity for a building block of the second, interlocking macrocycle. This knowledge made a simple synthesis of amide-linked rotaxanes possible. The first $\mathrm{X}$-ray structural analysis of a furano-catenane revealed a self-assembled, interlocked system held together by networks of inter- and intramolecular hydrogen bonds, including the amide groups and the furan oxygen atoms. There is no doubt that these new intertwined amide systems will be extendable to higher catenanes and rotaxanes.
\end{abstract}

Catenanes, rotaxanes and knots have become "Highlights" in supramolecular chemistry (1) thanks to more recent high yield syntheses via the use of supramolecular template effects (2).

\section{Amide-based catenanes}

During work on the syntheses of basket-shaped host molecules (3) we unexpectedly found an extremely simple catenane synthesis in 1992 (4). Catenane 3 could be prepared from the simple components 1 and 2 in one step (Scheme 1) (5). As byproducts, the dimethoxy-substituted macromonocycle 4 was isolated along with the 72-membered "tetramer" 5.<smiles>COc1cc(C(=O)Cl)cc(C(=O)Cl)c1</smiles>

1<smiles>Cc1cc(C2(c3cc(C)c(N)c(C)c3)CCCC2)cc(C)c1N</smiles>

2

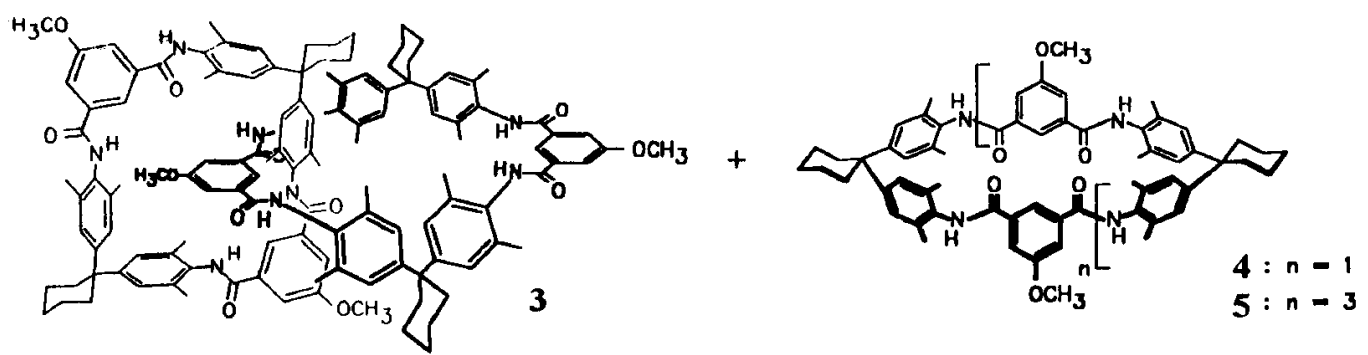

III

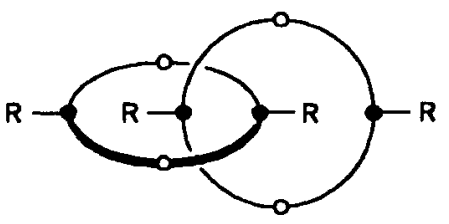

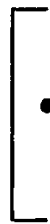<smiles>C=C1C=CC=C1C</smiles><smiles>[R]=C=Cc1cccc(C=O)c1</smiles><smiles>Cc1cc(C2(c3cc(C)c(N)c(C)c3)CCCC2)cc(C)c1N</smiles>

Scheme 1. One-step synthesis of the amide-based catenane 3 . 
So far we assume that "orthogonalisation", the perpendicular preorganization of the catenane building blocks is based on three templating effects: steric complementarity, hydrogen bonding between carbonyl oxygen atoms and amide protons, and $\pi-\pi$ interactions between the benzene rings of host and guest subunits. But which are the intertwining intermediate fragments ?

The selective formation of the isomeric disubstituted catenanes 6-8 and of the monosubstituted catenane 9 (Scheme 2) allowed conclusions concerning their mechanism of formation. The synthetic strategy which leads to the monomethoxy-substituted catenane 9 made it possible, for the first time, to obtain lactam catenanes with two different interlocking macrocycles.

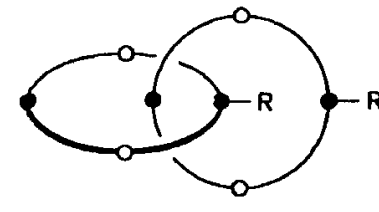

in/out

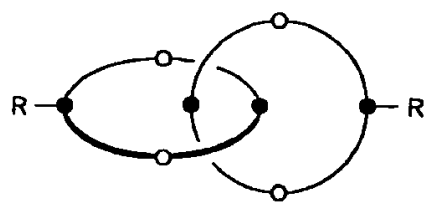

out/out

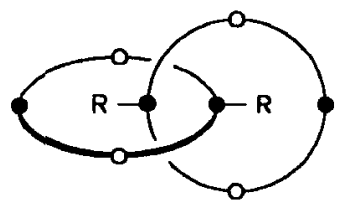

in $/$ in

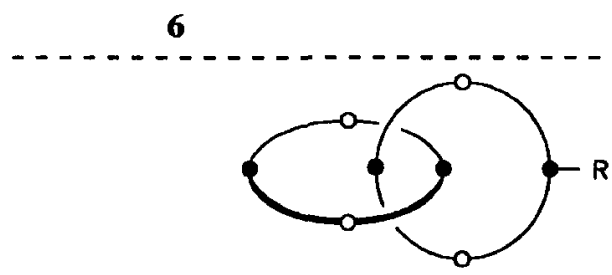

out

7

8

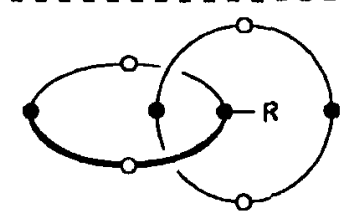

in

10

Scheme 2. The possible three isomeric disubstituted catenanes 6-8 and isomeric monosubstituted catenanes 9 and 10 .

The isomeric disubstituted [2]catenanes 6-8 were obtained by alternative routes (Scheme 3). The isomers 6 and 7 were prepared according to route $A$ in which the methoxy-substituted diamine 12 was reacted with isophthaloyl dichloride 11. The resulting mixture contained the substituted macromonocycle 14 (cf. Scheme 5) and the corresponding dimethoxy-substituted "tetramer" (cf. the tetramethoxysubstituted "tetramer" 5) besides the isomeric dimethoxy catenanes 6 and 7. The isomers were separated by column chromatography and show characteristic differences in their NMR spectra.

Route A

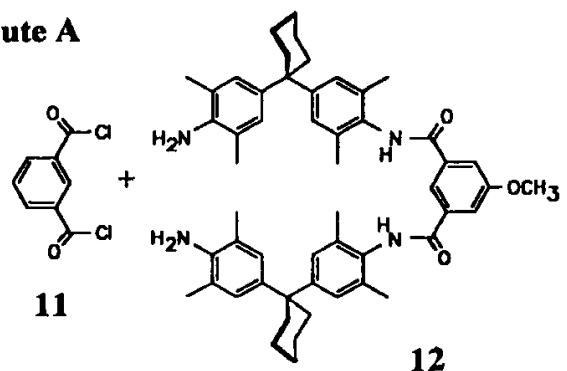

12

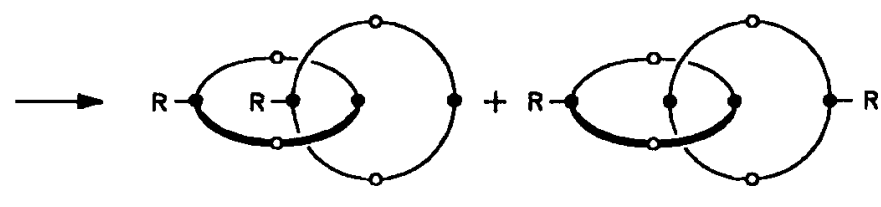

in/out

6

7

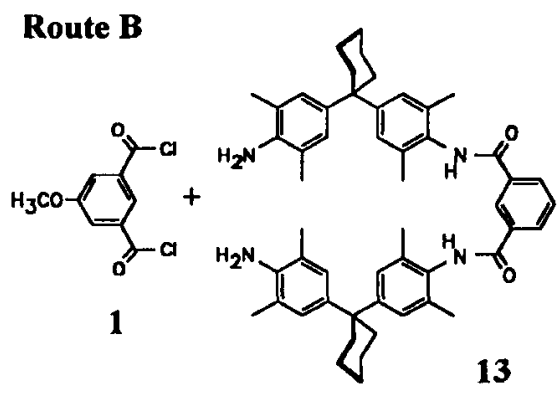

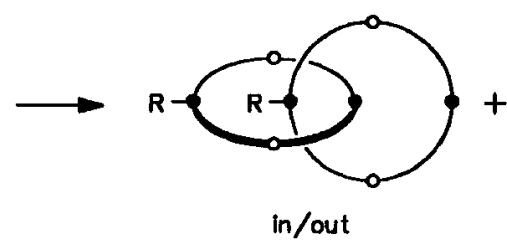

6

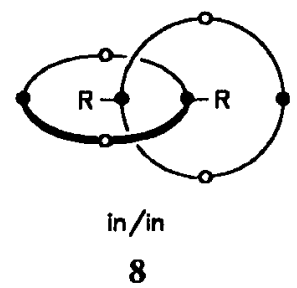

Scheme 3. Route A leads to a different set of dimethoxy-substituted catenanes $(6,7)$ than Route B $(6,8)$. 
In an attempt to synthesize the third dimethoxy-substituted catenane isomer 8 , we performed the reaction using starting materials with a reversed substitution pattern, i.e. 5-methoxyisophthaloyl dichloride 1 and the unsubstituted diamine 13 (route B). Besides the analogous monocycles, the catenane isomers 6 and 8 were found exclusively.

The route-dependent, selective formation of the stable isomers 7 and 8 allows conclusions to be drawn about the mechanism of ring interlocking. We assume that the supramolecular template effect, which is responsible for catenation, results from the respective diacid dichlorides $(1,11)$ lodging as guests inside the cavity of the host, the intermediate macromonocycle 14, in such a way that the metaphenylene ring of the guest is orthogonal to the ring plane of the host (Scheme 4). Yet we do not exchude the possibility that the isophthaloyl dichloride (1 or 11) already forms one amide bond with the corresponding diamine (12 or 13) before lodging inside the host. Because of the two isophthaloyl binding sites in the host cycle, there are two possible orientations (I, II and II, IV, respectively) for each acid chloride (1 and 11). Routes $A$ and $B$ thus lead to selective formation of isomers 7 and 8 , respectively, in addition to 6.

This mechanism provides an explanation for the significantly different yields of the catenanes obtained in routes A (6: $17 \%, 7: 23 \%)$ and $B(6: 2.7 \%, 8: 1.4 \%)$ : In the case of route B, the methoxy substituent on the diacid dichloride might cause steric hindrance in the host/guest complexes. Catenanes 6 and 8 in route $B$ should thus be formed in lower yields than 6 and 7 in route $A$.

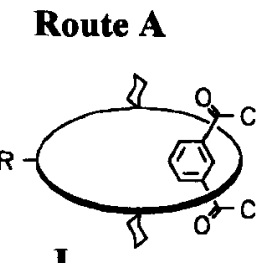

$\mathbf{I}$

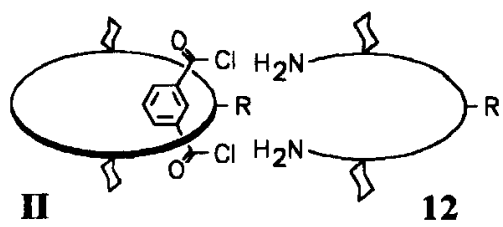

12

12
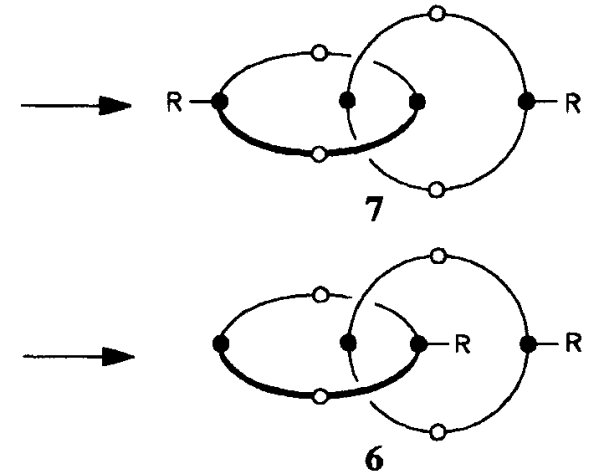

6

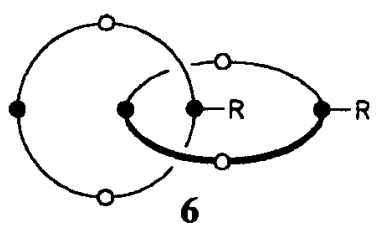

III

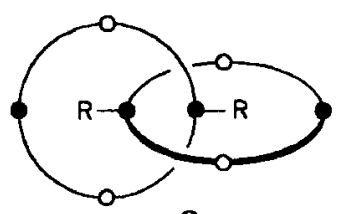

8

Scheme 4. The proposed template and orthogonalization mechanism (cf. I-IV) provides an explanation for the formation of different catenane isomers $(6,7$ and 6,8 ) in routes $A$ and $B$ (cf. Scheme 3 ). 
No interconversion or equilibration of the isomeric catenanes could be observed even at high temperature $\left(300{ }^{\circ} \mathrm{C}\right)$. The translation (circumrotation) of the rings seems to be hindered by the cyclohexylidene residues.

To provide further evidence for the hypothesis that the reaction proceeds via an intermediate monocycle of type 14, we carried out a synthesis following route $C$ (Scheme 5). Building blocks 11 and 13 were mixed in the presence of macrocycle 14 obtained as a byproduct in routes $A$ and $B$. Of the two possible monomethoxy-substituted isomers 9 and 10, only 9 was formed. The combination of the three reaction components 11,13 and 14 to form a single product is consistent with our proposed orthogonalization and interlocking mechanism shown in Schemes 4 and 5. Other mechanisms, in particular the interlocking of two open-chain fragments such as 11 with 12 or 12 with itself, do not appear to be significant.

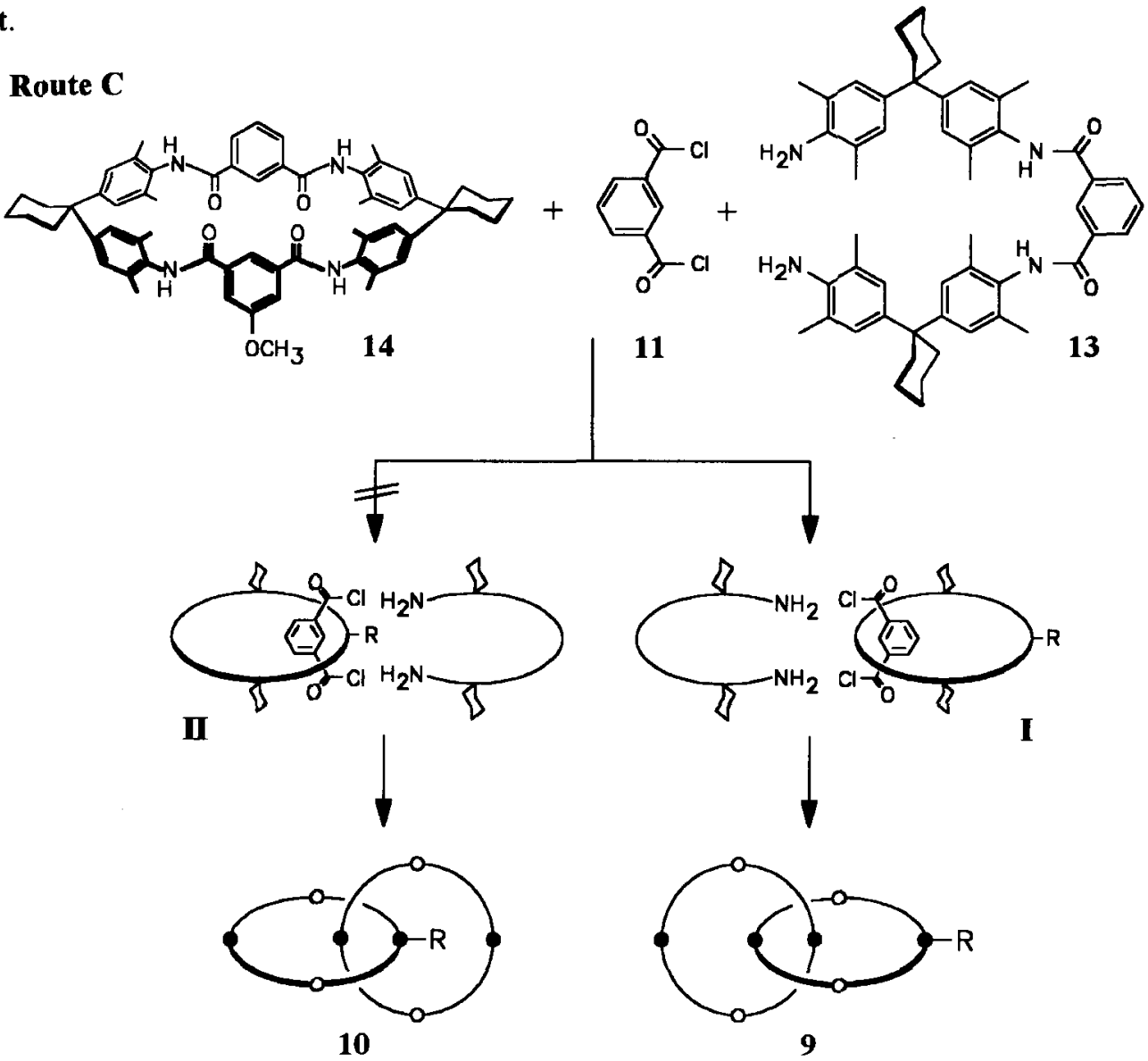

Scheme 5. Route C: The "catenation" of the macrocycle 14 with 11 and 13 leads to the formation only of the catenane isomer 9 . The guest diacid dichloride 11 and the host 14 are locked in an orthogonal arrangement (I).

The functional groups are fixed and thus preorganized for reaction with the diamine $\mathbf{1 3}$.

An advantage of route $C$ lies in the fact that the catenane 9 formed from the macrocycle 14 can be identified unambiguously from the molecular peak in the mass spectrum, because the isomeric macromonocycle (identical molecular mass) cannot be formed in route $\mathrm{C}$.

The orthogonalization and interlocking mechanism has farreaching consequences: In the future more reagents of types I-IV will become available, in which a host cavity (e.g. 14) and a (di)functionalized guest $($ e.g. 1, 11) are bound together by supramolecular interactions in an orthogonalized precatenane (prerotaxane, cf. I-IV) bearing two reactive groups. The synthesis of a variety of other catenanes by reaction with other partners becomes feasible. 
In order to gain further insight into the catenane formation we were interested in the consequences for the template mechanism arising from replacement of the metaphenylene subunits by different units. Therefore we carried out the synthesis D represented in Scheme 6 by reaction of the diaminofunctionalized diamide 13 with the dichloride of 2,5-furandicarboxylic acid 15 at high dilution. Here no catenanes could be detected, but the macromonocycle 16 was isolated in $15 \%$ yield.

We repeated the reaction with a "reversed pattern" (route E) by reaction of the diamide 17 with isophthaloyl dichloride 11. We again obtained 16 (4\% yield); however, in addition the catenane isomers 18 and 19 in 20 and $8 \%$ yield, respectively, were also produced. Whereas in both syntheses $D$ and $E$ the same macrocycle 16 is formed, only in the case of $E$ does the isophthaloyl dichloride 11 nest inside it, leading to catenane formation. It is remarkable that the analogous nesting of 2,5-furandicarboxylic acid dichloride 15 (or its open chain amide derivative) and its subsequent interlocking macrocyclisation in the course of D does not seem to occur to a comparable extent.
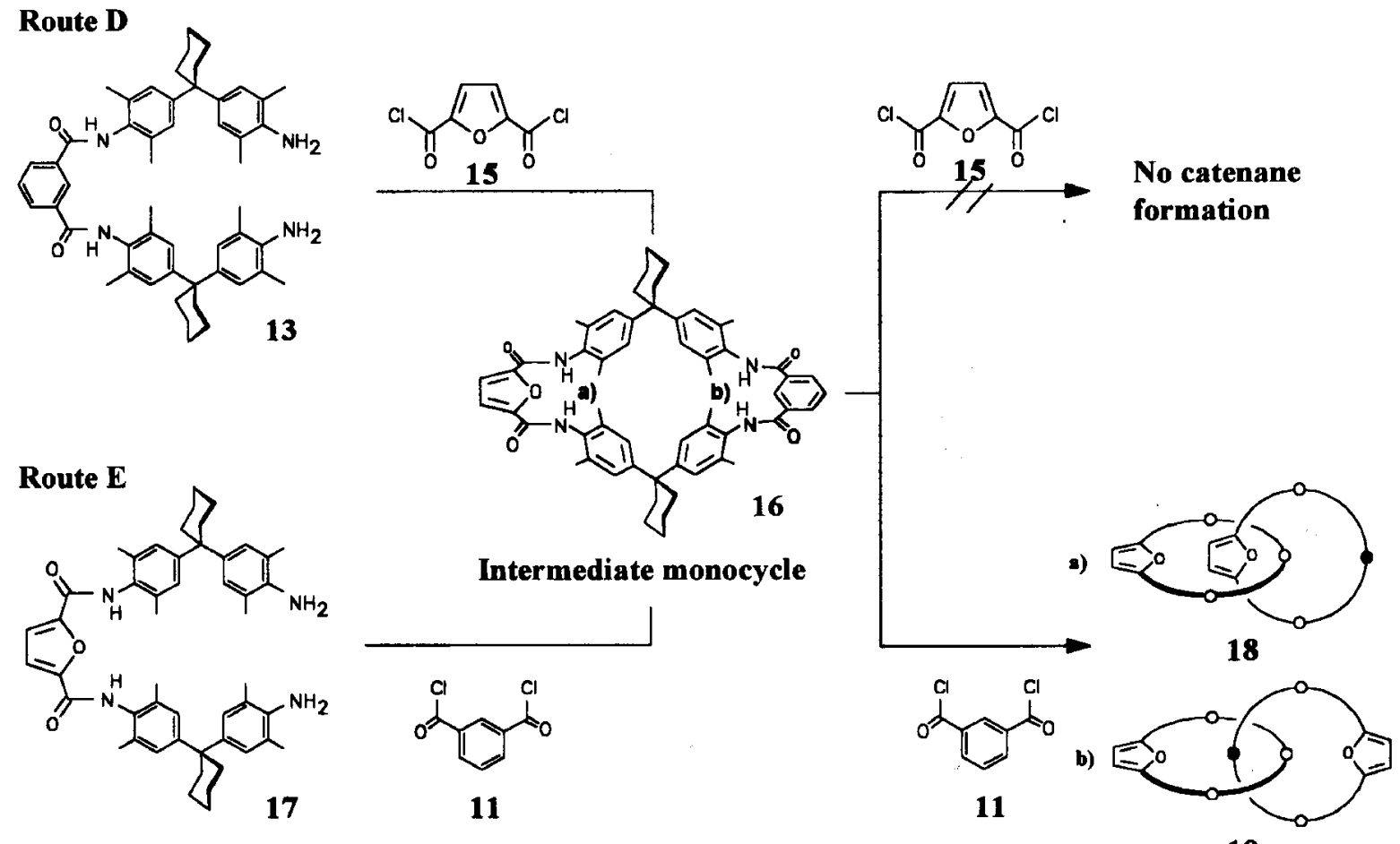

Intermediate monocycle

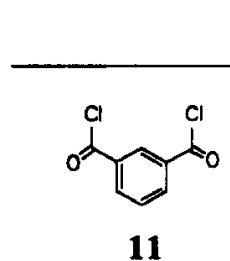

19

Scheme 6. Formation of the furano-catenane isomers 18 and 19.

From three possible difurano-catenane isomers, resulting from the hindered circumrotation of the catenane rings, we only observed the formation of 18 and 19 , which is in agreement with our proposed template mechanism. From the out/out and the in/out structure of these new catenanes it can be concluded that $\mathbf{1 1}$ is nested in such orientation inside the cavity of 16 that the second macrocycle is preferentially closed on the side near the furano ring of the first formed macrocycle 16. This means that there is a regioselectivity regarding the nesting of the guest in the two niches a) and b) of 16 (cf. Scheme 6): The template synthesis (16 acting as template cavity) is regioselective in a supramolecular sense; there is an intramolecular competition between the two niches or between two orientations a) and b) in 16 . 
The X-ray crystal structure of 19 was solved (Fig. 1), the first in this octaamide series (7). In the crystal, both 34-membered and structurally identical catenane rings which are composed of rigid building blocks, show the same conformation and are connected by numerous intra- and intermolecular hydrogen bonds. Each isophthaloyl moiety is buried in the cavity of the other macromonocycle, being involved in offset $\pi$-stacking interactions with two $m$-xylylene units. One of its carbonyl groups (trans-diamide) is hydrogen bonded to the amide proton of the second isophthaloyl unit. The other carbonyl group takes part in an unusual framework of hydrogen bonds connecting the two amide protons of the neighbouring furanoyl units and the furan oxygen. Two types of carbonyl groups (endo and exo) can be differentiated. The cis-diamide furanoyl carbonyl groups (exo) point to the exterior and form hydrogen bonds to adjacent methanol and catenane molecules. The isophthaloyl units contribute with their carbonyl groups (endo) to the hydrogen bonding interactions between the two intertwined macromonocycles.

\section{Amide-based rotaxanes}

On the basis of our above described hypothesis of the intertwining mechanism the syntheses of the first amide-based rotaxanes was successfully accomplished (8). Their (supramolecular template) syntheses are strikingly simple. The central part of the "axle" e.g. 11 is added to the "wheel" 22 and subsequently capped. The macromonocycle ("wheel") provides the receptor cavity for the "axle" and the triphenylmethane stoppers 25 confirm the mechanical bond between "wheel" and "axle".
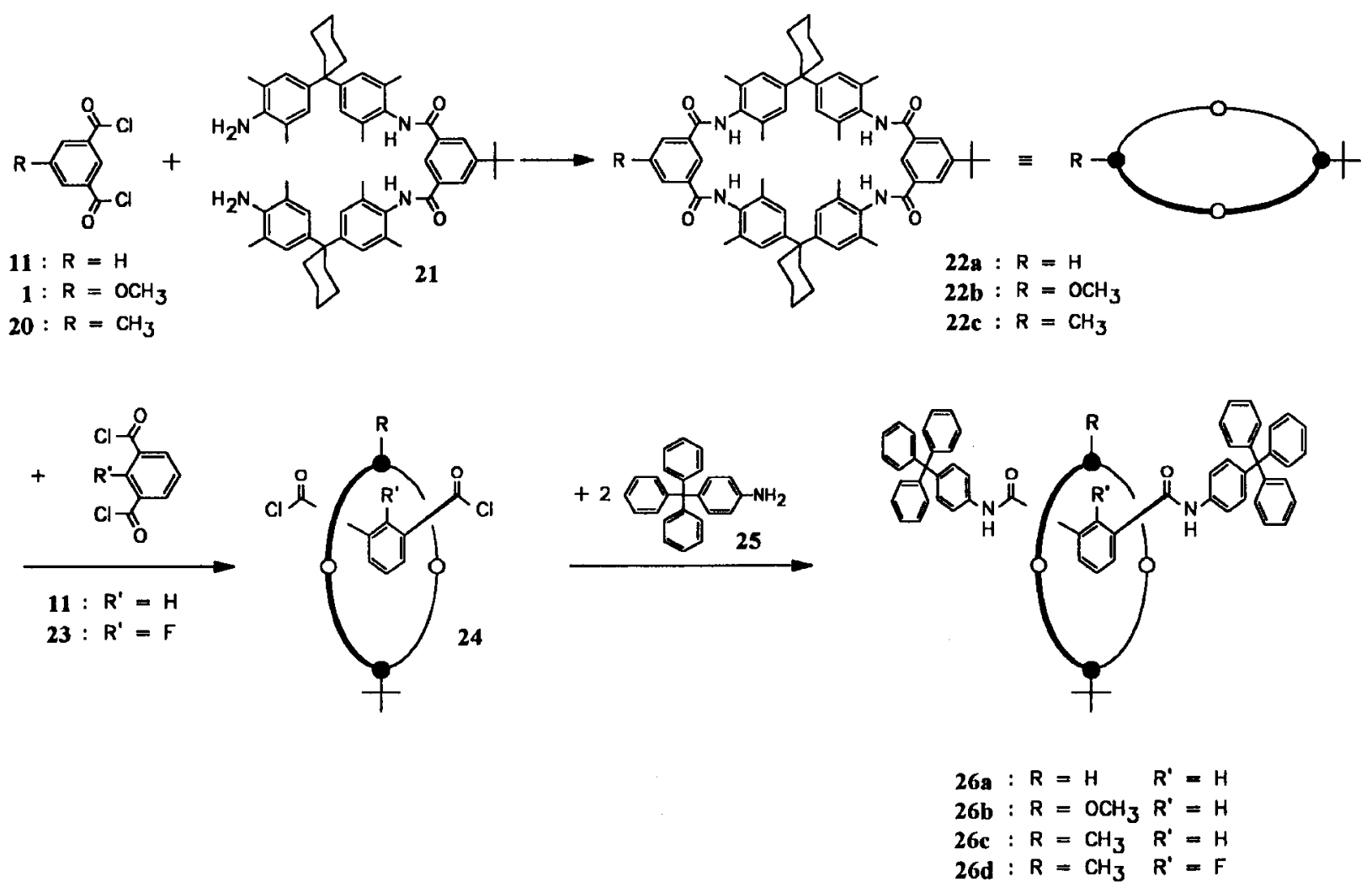

Scheme 7. Rotaxane synthesis: Isophthaloyl dichloride 11 (or its monoamide with 25) penetrates as guest the macromonocycle 22 which serves as the host. The resulting supramolecular intermediate 24 subsequently reacts with the stopper group 25 to form the rotaxane 26. 


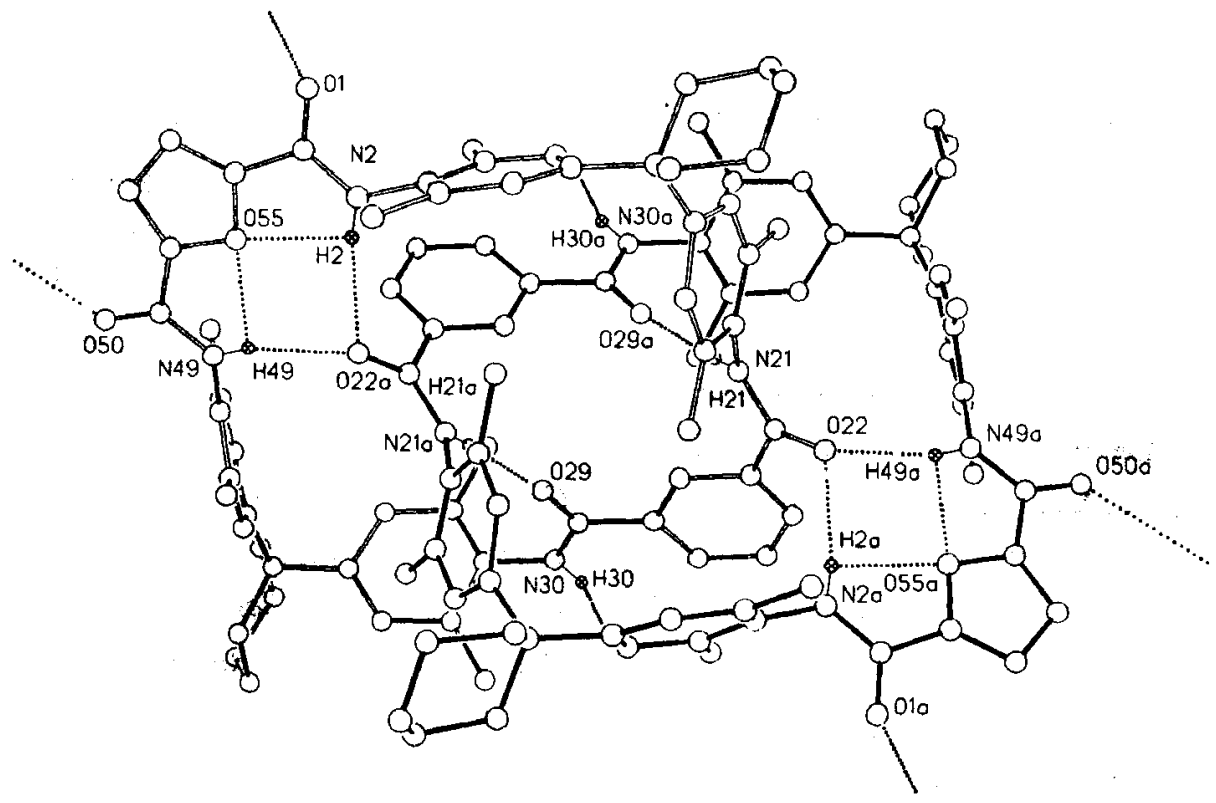

Fig. 1. X-ray structure of 19.
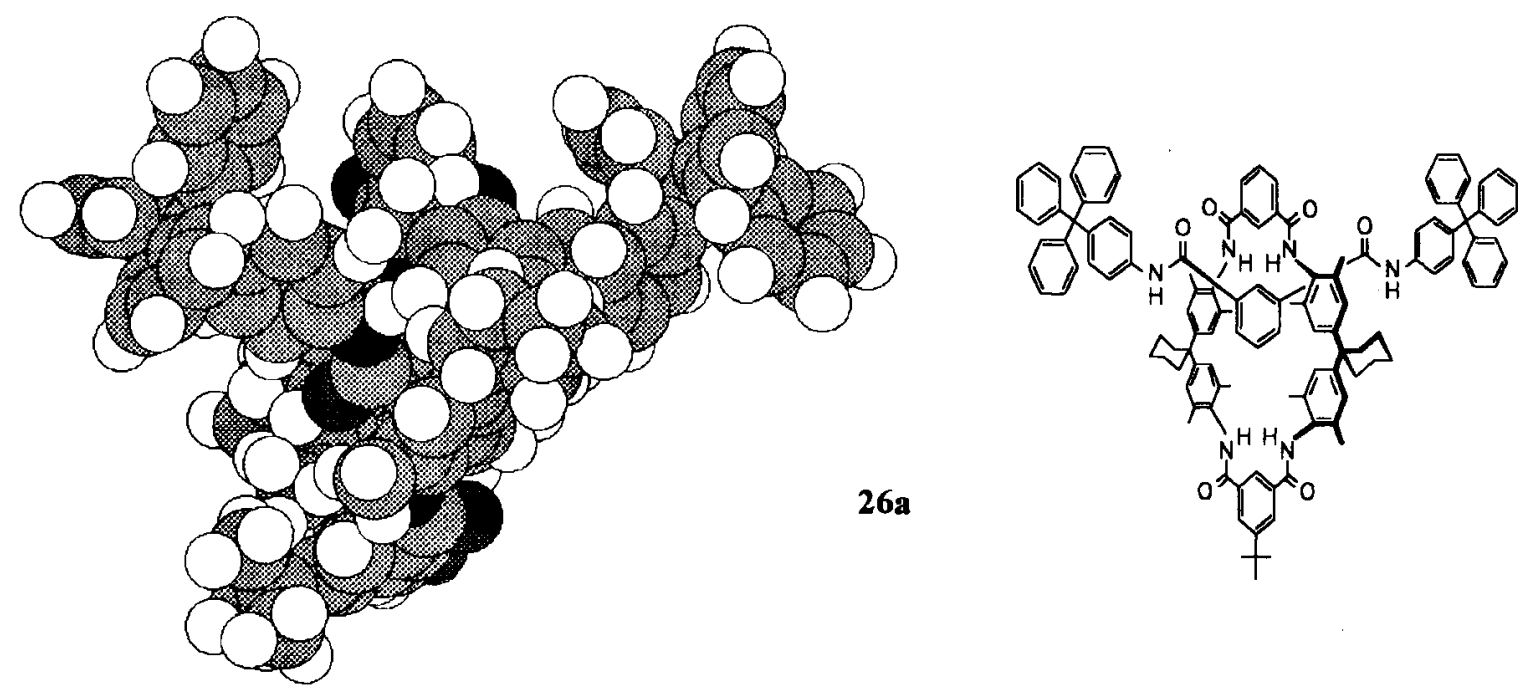

Fig. 2. Computer-generated space filling model of the rotaxane 26a (molecule geometry according to force-field calculations (9)).

\section{Conchusions}

This new approach to connect mechanical bonds seems to be one of the most simple and most general (10). Whereas other approaches need phenanthroline units acting as $\mathrm{Cu}^{+}$-template or 4,4-bipyridiniumcationic units leading to salt structures, the amide-based system is electrically neutral and needs no special complexing building blocks. The structural modifications carried out so far indicate that this system is very tolerant to exchanges of structural units. This means that many more [n]catenanes and [n]rotaxanes, and even knots may appear in the future the more so as yields will be no doubt optimized. It might even be possible to unite building (and especially templating) units of these main approaches into one and the same mechanically bound system. 
(1) a) For earlier catenanes see G. Schill, N. Schweickert, H. Fritz and W. Vetter, Angew. Chem. 95, 909 (1983); Angew. Chem. Int. Ed. Engl. 22, 889 (1983); Chem. Ber. 121, 961 (1988); D.M. Walba, R.M. Richards, M. Hermsmeier and R.C. Haltiwanger, J. Am. Chem. Soc. 109, 7081 (1987); D.M. Walba, Q.Y. Zheng and K. Schilling, J. Am. Chem. Soc. 114, 6259 (1992).

b) See for example C.O. Dietrich-Buchecker, J. Guilhem, C. Pascard and J.-P. Sauvage, Angew. Chem. 102, 1202 (1990), Angew. Chem. Int. Ed. Engl. 29, 1154 (1990).

c) P.R. Ashton, T.T. Goodnow, A.E. Kaifer, M.V. Reddington, A.M.Z. Slawin, N. Spencer, J.F. Stoddart, C. Vincent and D.J. Williams, Angew. Chem. 101, 1404 (1989); Angew. Chem. Int. Ed. Engl. 28, 1396 (1989); D. Philp and J.F. Stoddart, Synlett 1991, 445.

d) M. Fujita, F. Ibukura, K. Yamaguchi and K. Ogura, J. Am. Chem. Soc. 117, 4175 (1995).

e) P.R Markies, T. Nomoto, O.S. Akkerman and F. Bickelhaupt, J. Am. Chem. Soc. 110, 4845 (1988); G.-J.M. Gruter, F.J.J. de Kanter, P.R. Markies, T. Nomoto, O.S. Akkerman and F. Bickelhaupt, J. Am. Chem. Soc. 115, 12179 (1993).

f) Y. Geerts, D. Muscat and K. Müllen, Macrom. Chem. Phys. 1995, submitted.

g) G. Brodesser, R. Güther, R Hoss, S. Meier, S. Ottens-Hildebrandt, J. Schmitz and F. Vögtle, Pure \& Appl. Chem. 65, 2325 (1993).

(2) R. Hoss and F. Vögtle, Angew. Chem. 106, 389 (1994), Angew. Chem. Int. Ed. Engl. 33, 375 (1994); S. Anderson, H.L. Anderson and J.K.M. Sanders, Angew. Chem. 104, 921 (1992), Angew. Chem. Int. Ed. Engl. 31, 907 (1992); S. Anderson, H.L. Anderson and J.K.M. Sanders, Acc. Chem. Res. 26, 469 (1993).

(3) L. Wambach and F. Vögtle, Tetrahedron Lett. 26, 1483 (1985); B. Dung and F. Vögtle, J. Incl. Phenom. 6, 429 (1988); J. Breitenbach, K Rissanen, U.U. Wolf and F. Vögtle, Chem. Ber. 124, 2323 (1991); C. Seel and F. Vögtle, in Perspectives in Coordination Chemistry (Eds.: A.F. Williams, C. Floriani, A.E. Merbach), p.31, VCH, Weinheim (1992).

(4) F. Vögtle, S. Meier and R. Hoss, Angew. Chem. 104, 1628 (1992); Angew. Chem. Int. Ed. Engl. 31, 1619 (1992).

(5) Catenane 3 with $R=H$ was independently prepared with remarkable yield (34\%) in a two step synthesis starting from the isolated intermediate 13 and isophthaloyl dichloride 11: C.A. Hunter, J. Am. Chem. Soc. 114, 5303 (1992); see also C.A. Hunter and D.H. Purvis, Angew. Chem. 104, 779 (1992), Angew. Chem. Int. Ed. Engl. 31, 792 (1992).

(6) S. Ottens-Hildebrandt, S. Meier, W. Schmidt and F. Vögtle, Angew. Chem. 106, 1818 (1994), Angew. Chem. Int. Ed. Engl. 33, 1767 (1994).

(7) S. Ottens-Hildebrandt, M. Nieger, K. Rissanen, J. Rouvinen, S. Meier, G. Harder and F. Vögtle, J. Chem. Soc., Chem. Commun. 1995, 777.

(8) F. Vögtle, M. Händel, S. Meier, S. Ottens-Hildebrandt, F. Ott and T. Schmidt, Liebigs Ann. 1995, 739.

(9) We express our gratitude to Dipl.-Chem. J. Osterodt, Universität Bonn, for the preparation of the computer-generated model; MM+: Autodesk HyperChem ${ }^{\text {TM }}$ 2.0; N.L. Allinger, J. Am. Chem. Soc. 99, 8127 (1977).

(10) In preliminary experiments we were already able to introduce building units such as sulfonamide groups (11), terephthalic acid units, podand units and deuterium labels.

(11) S. Ottens-Hildebrandt, T. Schmidt, J. Harren and F. Vögtle, Liebigs Ann. 1995, in press. 